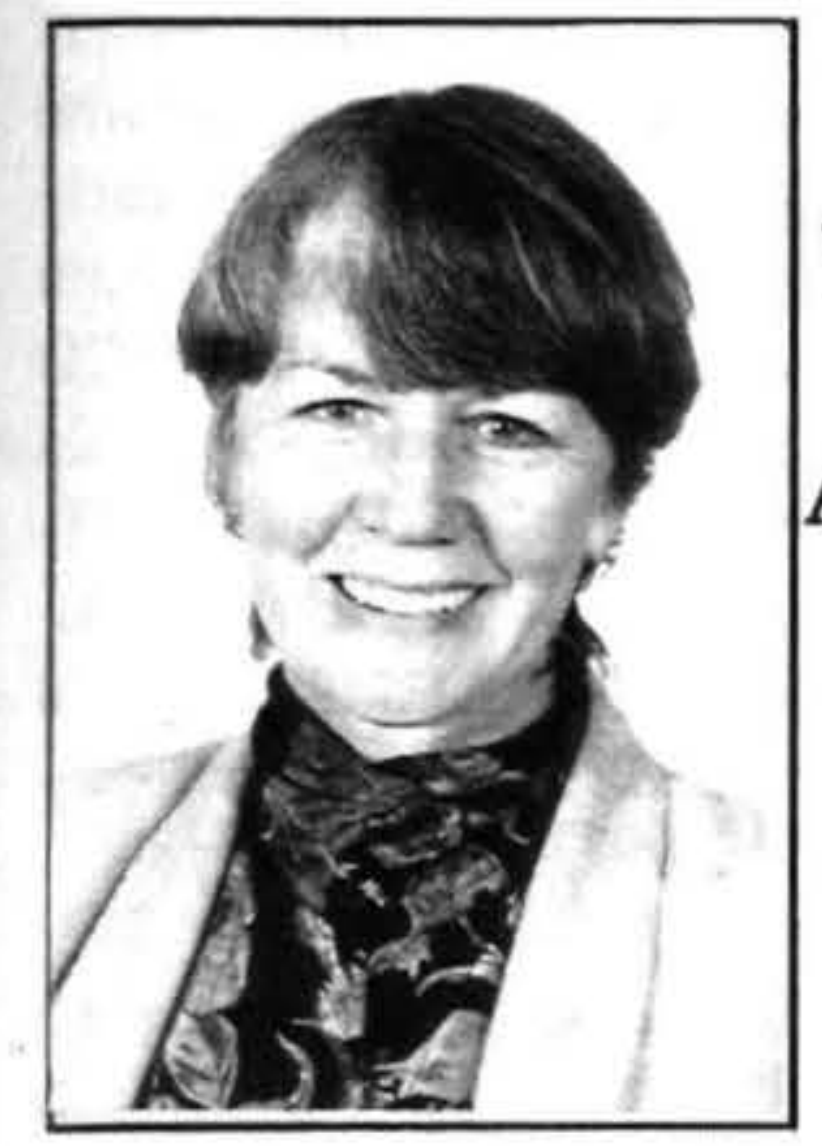

\title{
YOUTH UNEMPLOYMENT AND THE 'INVISIBLE HAND' - A CASE FOR A SOCIAL MEASURE OF UNEMPLOYMENT
}

\author{
Natalie Jackson
}

University of Waikato

\begin{abstract}
This paper considers the relationship between youth unemployment, the 'invisible hand', and increasing youth dependency. Empirically, it shows that conventional measures of unemployment ofien conceal more than theyreveal. This is because they are based on labour force participation rates which differ both between different age, sex, and ethnic groups, and across time; and because the analyses are usually cross-sectional. The paper argues that such measures contribute to (i) superficial interpretations of the causes of youth unemployment (and unemployment in general); (ii) misleading impressions of the degree to which each group is exposed to (that is, 'carrying' the consequences of) unemployment; and therefore can lead to (iii) inappropriate policy responses. An alternative population-based index is proposed, and a more illustrative cohort perspective of unemployment is given. In combination with a brief review of associated demographic factors, the results place in doubt the current wisdom of permitting the 'invisible hand' to manage contemporary unemployment.
\end{abstract}

\section{Unemployment in New Zealand: perceptions and panaceas}

Figure 1 is derived from Registered Unemployment statistics. While these - in the words of their own compilers 'are not a reliable source of labour market information' (NZES, 1992:2), as a guide they show that between the 1940 s and early 1970 s, unemployment did not even register on the scale needed to incorporate contemporary rates. The first large increase occurred in the six months between September 1977 and March 1978, when the numbers of registered unemployed more than doubled, from just over 8,000 , to nearly 20,000 (NZES, 1992).

At that time, no social or economic policies to deal with

Figure 1. Number on unemployment register, 1946 to 1994.

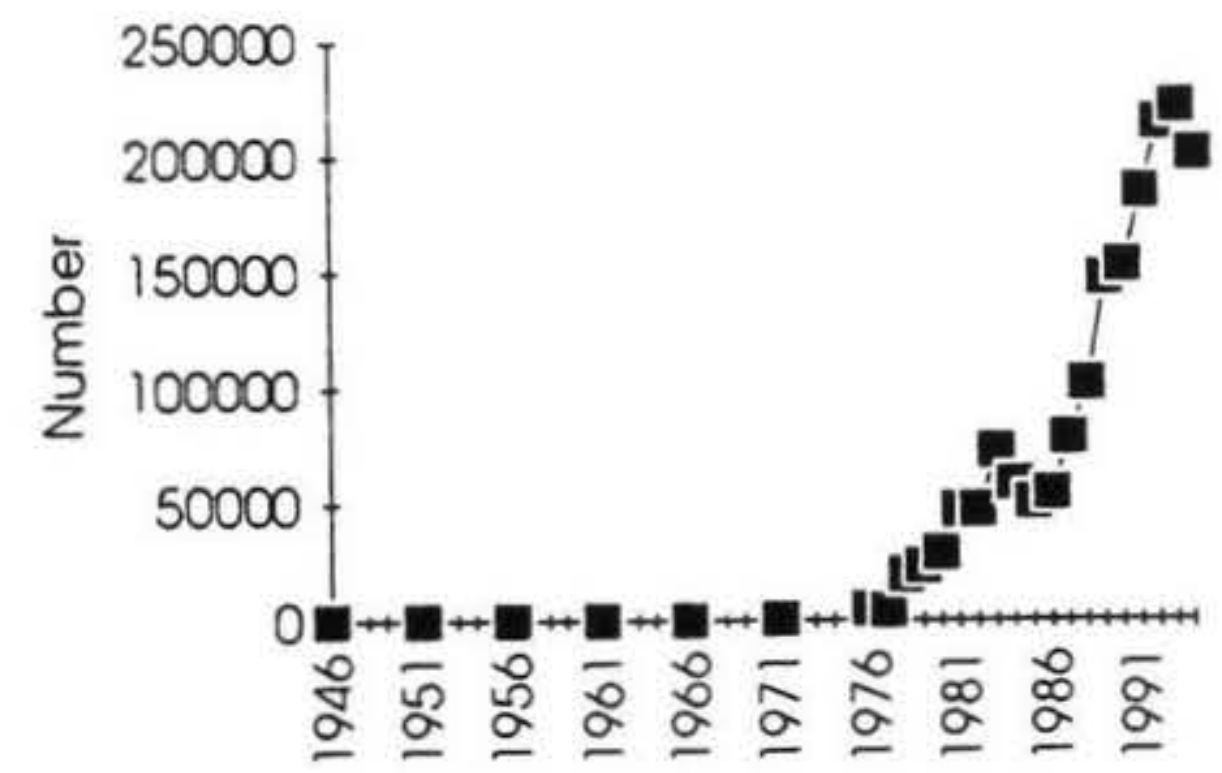

Source: New Zealand Employment Service unemployment were developed. Instead, politically voiced concerns with 'Polynesian overstayers' shifted the emphasis from unemployment to one of law and order, and dawn raids saw the 'offending parties' rounded up and deported, and migration policy tightened (Spoonley, 1988). ${ }^{1}$

Over the ensuing years, the continually rising unemployment rate attracted a variety of explanations and responses. These ranged from the state's acknowledgment in the early 1980 s that the job shortages were the result of structural changes beyond the control of the individual ${ }^{2}$ (Bolger, 1981), and resulting in a broad range of job creation schemes; to, in the mid-1980s, a significant reframing of the problem as proof of the success of the state's macroeconomic policies, the significant 'labour shedding' reflecting previously inefficient industries and management practices $^{3}$ (Treasury, 1987; OECD Economic Survey, 1988-89:38-41); and, by 1991, to a major concern that a 'culture of dependency' was at the root of the problem (New Zealand Business Roundtable, 1988, 1990; Shipley et al., 1991). ${ }^{4}$

In keeping with these increasingly neo-liberal attitudes (Oliver 1989; Easton et al., 1989), there followed a major restructuring of the welfare state, accompanied by the essentially inter-related Employment Contracts Act (Bolger, Richardson, and Birch, 1990; Shipley et al., 1991; Boston and Dalziel, 1992; Walsh, 1992; Shirley, 1993) ${ }^{5}$. The changes encompassed both substantial reductions in welfare benefits and severe restrictions in eligibility of access to them, which passed a large portion of the responsibility for welfare needs from the State to the "Core 
Family ${ }^{\prime}{ }^{6}$ a significant attack on the real wage; and a massive scaling down of the job schemes, from more than 42,000 in September 1984 to fewer than 11,000 by March 1992 (NZES, 1992).

In 1992, with registered unemployment well over 200,000 , the 'lack of appropriate skills' thesis began to make headlines. This was met (some might think, paradoxically) with more neo-liberal policy: a significant increase of the cost of tertiary education, and greatly restricted elibility for student allowances, both of which, needless to say, imposed further costs on the family. Finally, in early 1994 , the first signs of a steadily falling unemployment rate saw the 'problem' again revert to the negative, but this time as a threat to the much vaunted 'economic recovery. ${ }^{8}$ Since then concerns with higher spending (presumably by the more securely employed) have returned the policy focus to the inflationary effects of this recovery, and falling unemployment is being looked upon with some trepidation. For the Free Market experimenters this should not be too much cause for concem, however: the Consensus Unemployment Forecast (given at this conference by the Department of Labour) projects a minimum unemployment rate of not less than six per cent until at least March 1987.

There are of course many other explanations of unemployment, too numerous to mention here. Those that have been serve to illustrate the old axiom that how a problem is defined (at least politically) by and large determines the response. Two important things seem to have been missing, however. The first is a lack of continuing public acknowledgment that New Zealand's relatively high unemployment in the 1990s (still one of the highest of the OECD countries) is an expected consequence of the disinflation and trade liberalisation policies which have fundamentally underlain the restructuring, and now recovery, of the economy (Treasury, 1987:201-2; OECD Economic Survey, 1988-89; Oliver, 1989; Easton et al., 1989; Shirley, Easton, Briar and Chatterjee, 1990; Boston and Dalziel, 1992; Shirley, 1993). Such policies pertain more to the 'law of diminishing returns', whereby strategies to improve the profits of capital must be facilitated, in this case by the State, than they do to, for example, a culture of dependency. The second, and related, point, is that the full employment experienced in the advanced capitalist economies over the 1950s and 1960s by and large owed its presence to the post-war boom. The factors which sustained it - the baby boom demand for consumer goods; high productivity; and relatively low cost of raw materials, - have now slackened and changed, possibly permanently (Touraine, 1991:7-8).

This brings us to the main point of this paper. In the mid1980 s it was argued by the Organisation for Economic CoOperation and Development (OECD, 1985:9-11) that, whatever the specific reasons for unemployment, the phenomenon was going to effect an 'at-risk' generation, defined not in terms of age, but as a cohort bom, in most OECD countries, between the late 1950 s and early $1960 \mathrm{~s}^{9}$. Since New Zealand's baby boom occurred slightly later and lasted slightly longer than its international counterparts (Pool and Sceats, 1981:9), this argument relates to the cohorts born in the early 1970 s, those now in their early twenties. Arguing that 'it will be years before youth unemployment can be brought under control', the OECD proposed that countries develop policies which would follow this cohort as a moving target (OECD, 1985:1113), a suggestion reiterated by both New Zealand's Population Monitoring Group (PMG) in 1986, and its Royal Commission on Social Policy (RCSP) in 1988, but apparently disregarded by New Zealand's policy-makers.

Undoubtedly, the failure to follow such advice can be linked to the significant theoretical and ideological shift which has taken place in New Zealand's policy-making over the past two decades. However, it is equally fair to say that two issues contribute quite considerably to the problem of understanding and responding to unemployment: the way it is measured; and a lack of appreciation of the demographic change which ultimately underpins both the supply of, and demand for, labour, and the capacity of the family to support its unemployed members (Jackson, 1994). Unless these are incorporated into the analysis of unemployment, the decision-making base will be inadequate. We turn first to the measurement of unemployment.

\section{Measuring unemployment}

The first point is that there is not, nor can there be, any absolute or definitive measure of either the labour force or any component of it, such as unemployment. At all times these are simply reflections of the definitional criteria being used They include:

\section{1. the definition of 'work' itself (only formal, 'active' engagement);}

2. the hours which denote full- or part-time participation;

3. whether or not part-time is included in the labour force;

4. the criteria for determining unemployment.

These issues have been well covered elsewhere, so will not be dwelt on here. Suffice it to say that one gets different levels of labour force participation and unemployment depending on which collection is used and the period of observation, and that unemployment is almost always underenumerated. ${ }^{10}$ In addition, however, there is a rather less commonly discussed problem. Levels of participation in the labour force are markedly different for different agegroups, for men and women, and for different ethnic groups (the classification of ethnicity is also very problematic, but cannot be dealt with here). Middle aged males, for example, have (historically) higher levels of participation than either younger males or women of their own age; men in general have higher participation rates than women; and Maori and Pacific Islanders have sometimes higher, sometimes lower, levels of participation than their Pakeha counterparts. Since 1986, participation rates have fallen for almost all groups, but considerably more so for Maori, Pacific Islanders, and 15-19 year olds. Comparisons of labour force-based unemployment between each group are 
thus considerably compromised. Moreover, they give only the 'incidence' of unemployment (the number of cases per those 'working'), not its 'prevalence' (the level of exposure that a group must accommodate).

In the statistical analysis that follows I will use both labour force and population denominators. My rationale for using the latter is that it 'controls' for many of the problems just mentioned: the denominator is always relative to the actual number of people in any age- sex- ethnic-group, not merely those participating in the labour force, and it simultaneously gives the 'level of exposure' to unemployment of each group. ${ }^{11}$ I am familiar with the arguments which oppose this measure, maintaining that only those who are in the labour force can ever be considered as unemployed, or even 'exposed to the risk' of becoming unemployed. I would like therefore to make a distinction between the economic measurement of unemployment (which pertains to stocks and flows), and the social measurement (which pertains to unemployed people), whereupon the impact of unemployment on a group can be more validly ascertained. At the micro-level, where the experience of unemployment is lived out, it is all these people who must accommodate the consequences of this exposure.

Figures 2 and 3 compare unemployment by age and sex, using first the labour force-based, and then the populationbased, measure. ${ }^{12}$ It can be seen that when the labour force denominator is used, the 15-19 year old unemployment rate shows a steep incline over the 1986-91 period; but when the population denominator is used, the trajectory between these points 'drops' dramatically (in 1991, to 1 in 8 , as opposed to 1 in 4 with the labour force measure). As can be inferred from above, this occurs simply because those who are not in the labour force cannot appear in the

Figure 2. Unemployed as percentage of age-group in labour force, by sex, 1976 to 1991.
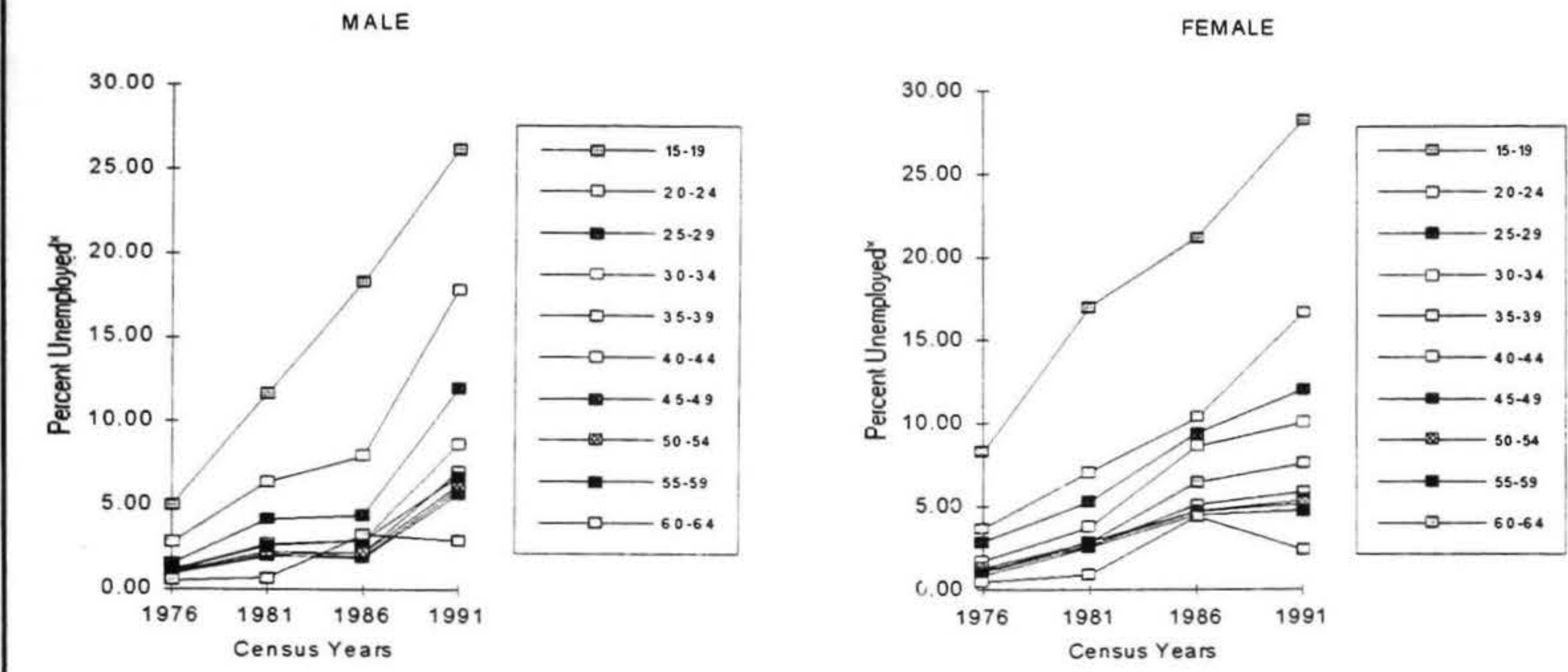

Figure 3. Unemployed as percentage of total age-group, by sex, 1976 to 1991

MALE

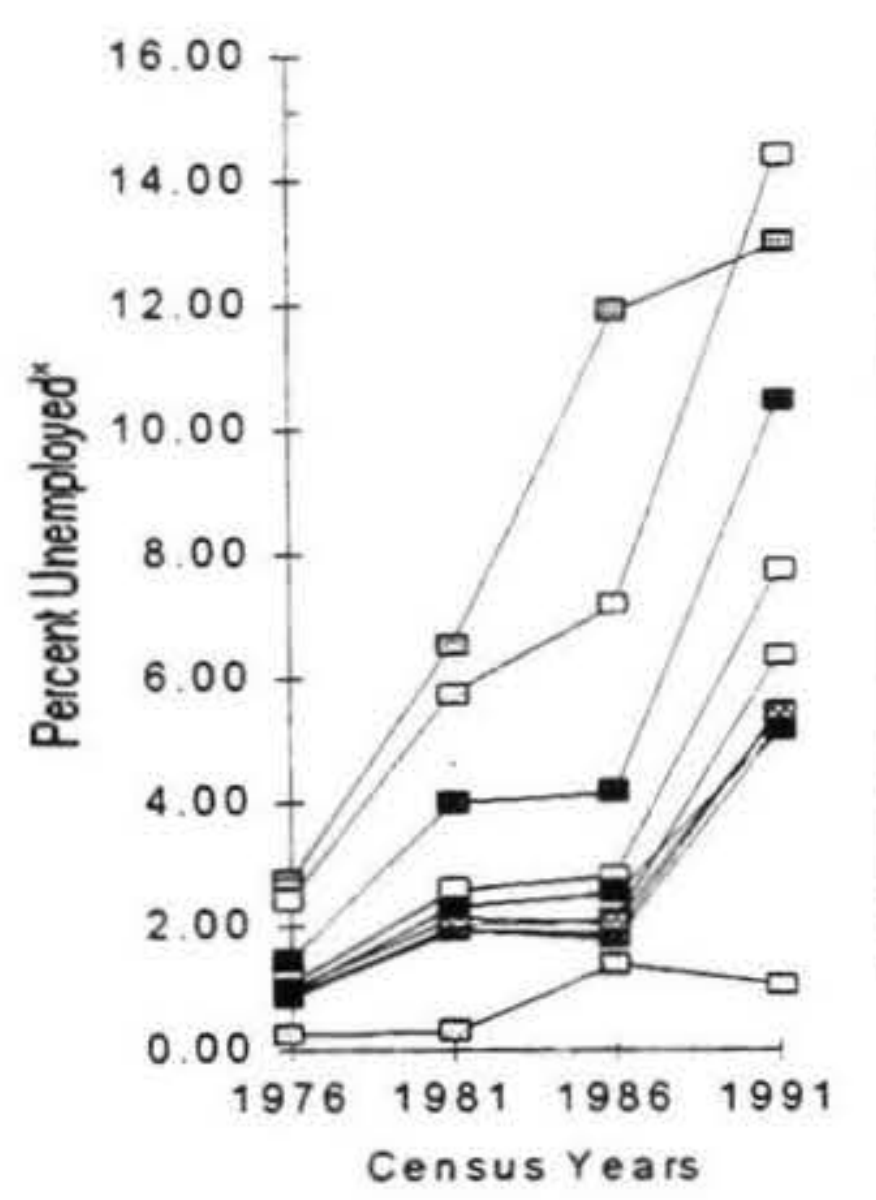

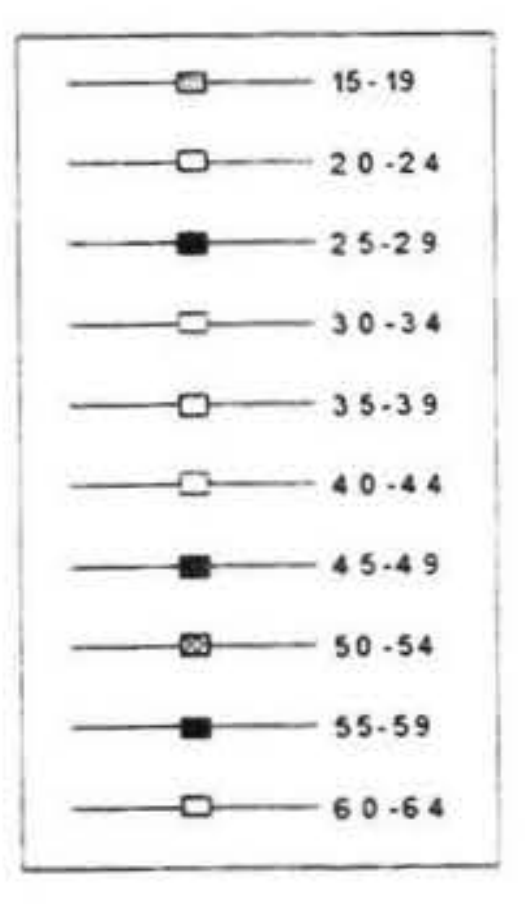

- For $1976+1981$ Unemployment refers to FULL-TIME only

For 1986 + 1991 Unemployment refers to Full-time PLUS Part-time
FEMALE

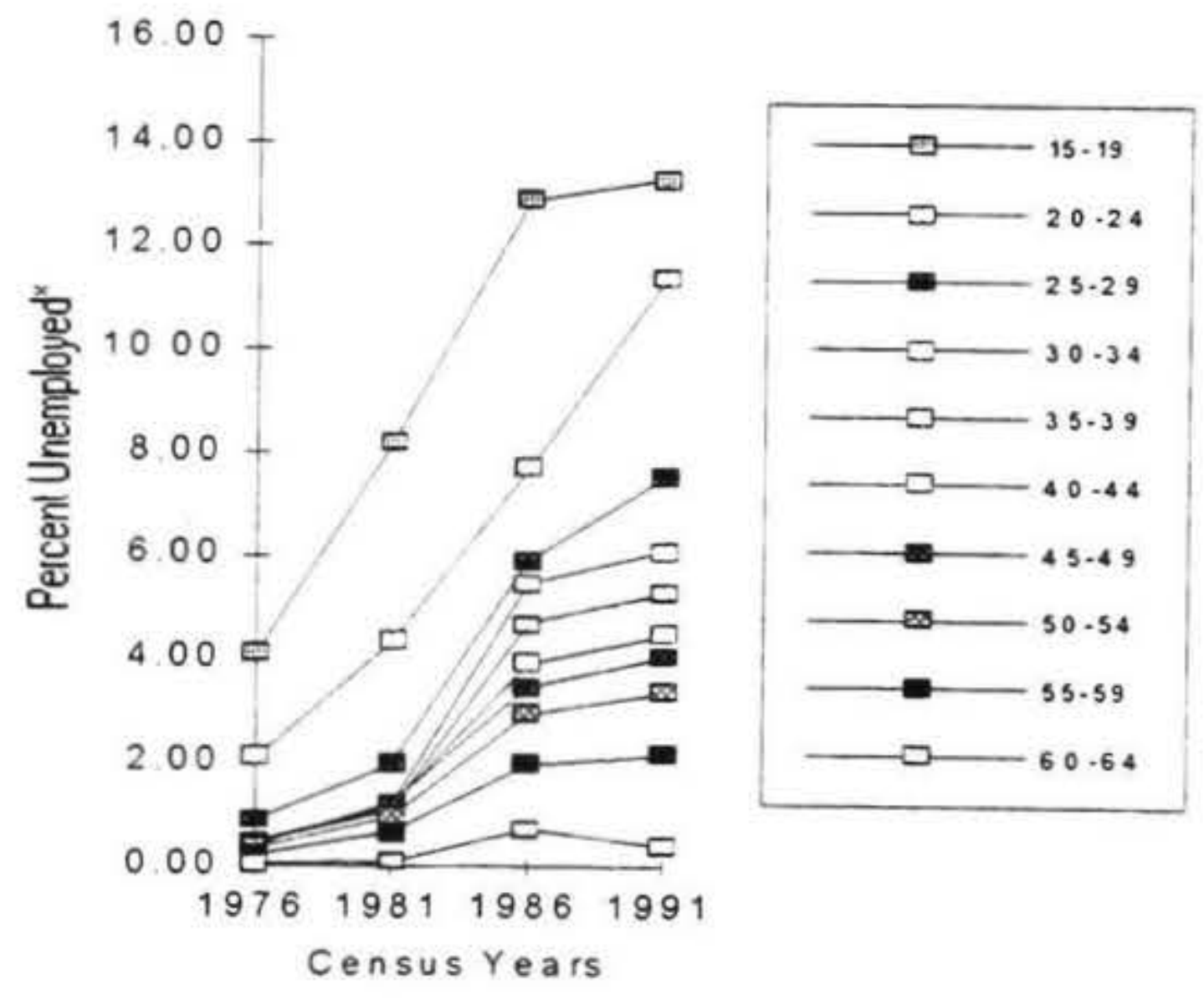


unemployment numerator (it stays the same for both measures), but they do so in the population denominator. Since the population denominator is considerably larger than the labour force denominator, it makes the unemployment rate drop, or appear to. The inclusion of part-time work in the labour force since 1986 adds a further dimension to this situation. Obviously, the larger the denominator, the lower the level of unemployment will appear to be. Because part-time unemployment is generally lower than fulltime, when part-time unemployment is added to the numerator, and part-time employment plus unemployment to the denominator, the resulting unemployment rate is lowered further. ${ }^{13}$

Conversely, the population based measure scarcely alters the 20-24 year and older unemployment trajectories. This reflects both the higher labour force participation rates of these age groups, and the fact that relatively greater numbers of the potential unemployed are already included in this measure. It also, however, identifies the very heavy burden of actual unemployment being carried by 20-24 year olds ( 1 in 8 , the same as $15-19$ year olds), a perspective which contrasts significantly with the labour force based measure. This is the cohort identified by the OECD, the PMG, and the RCSP.
Clearly, what is shown in figure 3 was not a true improvement in youth unemployment between 1986 and 1991, as HLFS and Registered Unemployed statistics confirm. Rather, it would appear that we have reached somewhere near saturation amongst the teenage population, potential unemployment undoubtedly hiding in schools, tertiary institutions, and in those jobschemes still available, amongst discouraged workers, young mothers, etc (Horsfield and Evans, 1988). While some of this may be advantageous in the long run, it should not be overlooked that such people become 'invisible' statistics: with the age of eligibility for the adult rate of unemployment benefit now 25 years, these persons in reality constitute varying degrees of 'invisible' dependency, on their parents, spouses or partners. As figure 4 shows, this is a factor which has considerable pertinence for the Maori and Pacific Islands populations, for whom proportionately greater numbers of youth appear to be staying out of the labour force.

In relation to the notion of youth dependency is another perspective of unemployment, that of the proportion of all unemployment that each age-group carries. Figure 5 shows that while 15-24 year olds carried 62 per cent of all unemployment in 1976 , by 1991 this was down to 44 per cent. The older age-groups, to which their parents belong, have been increasing their share, from 38 per cent in 1976

\section{Figure 4. Male unemployment*: percent of age group in population by ethnicity, 1976}

to 1991

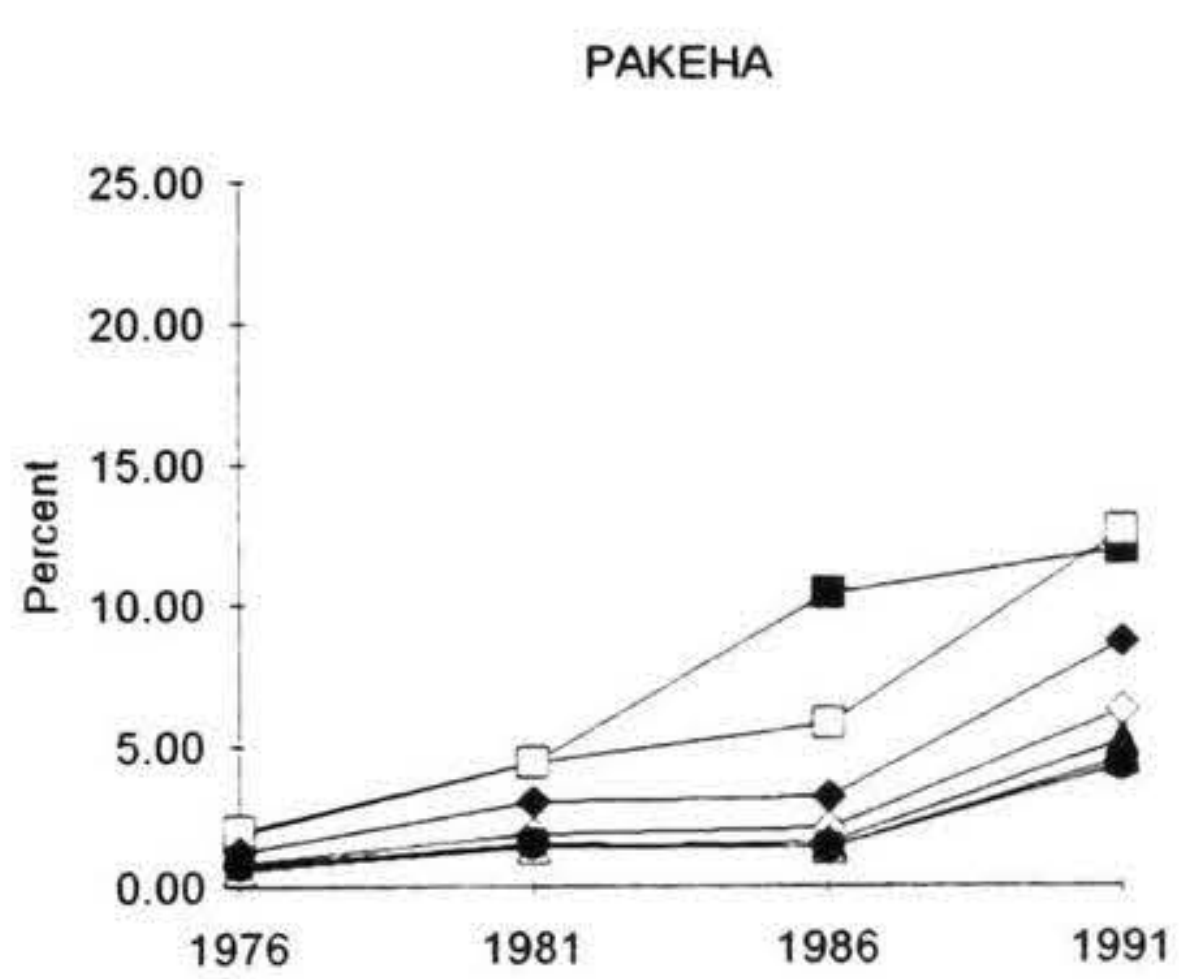

ASIAN/OTHER

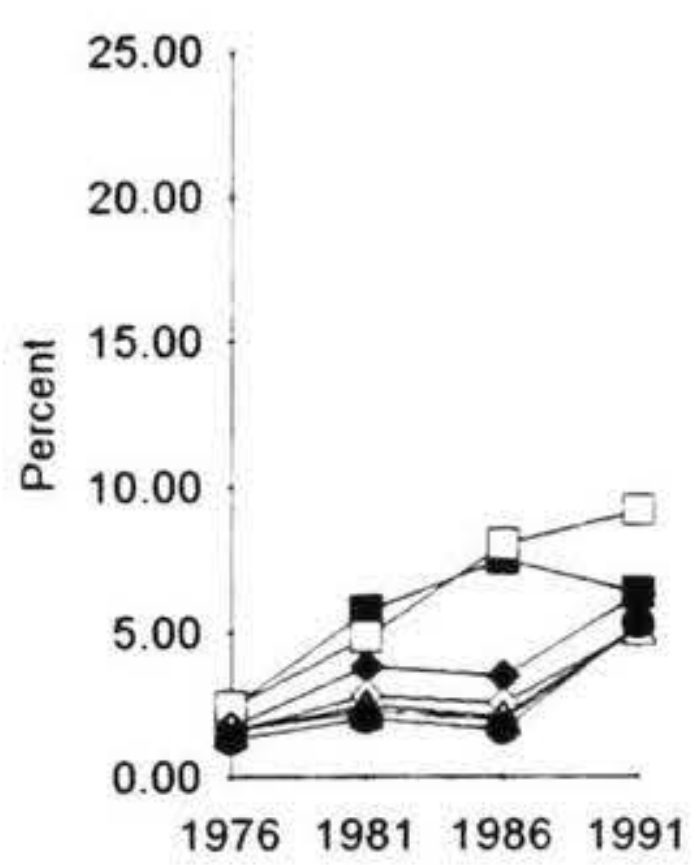

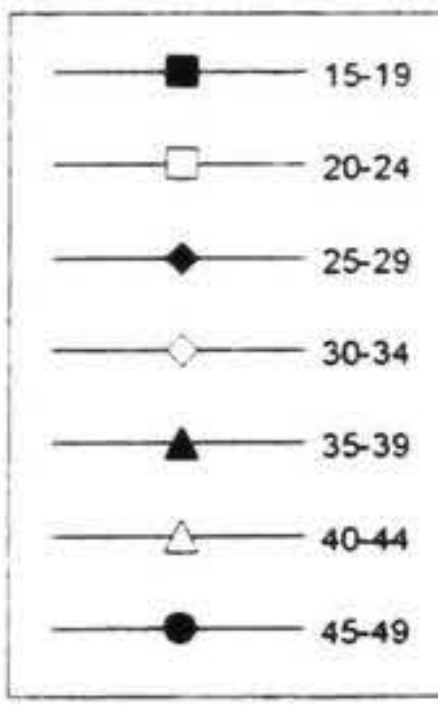

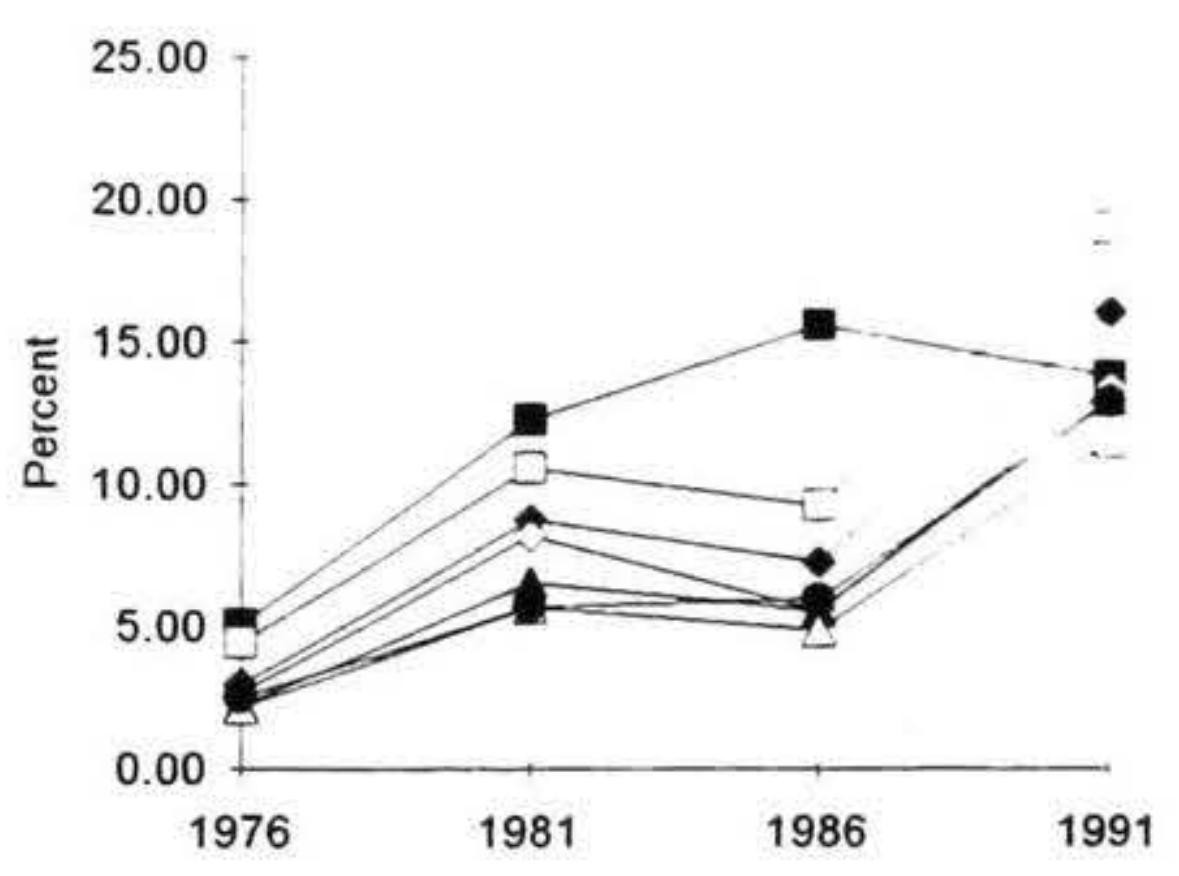


Figure 5. Age distribution of total unemployment*, 1976 to 1991
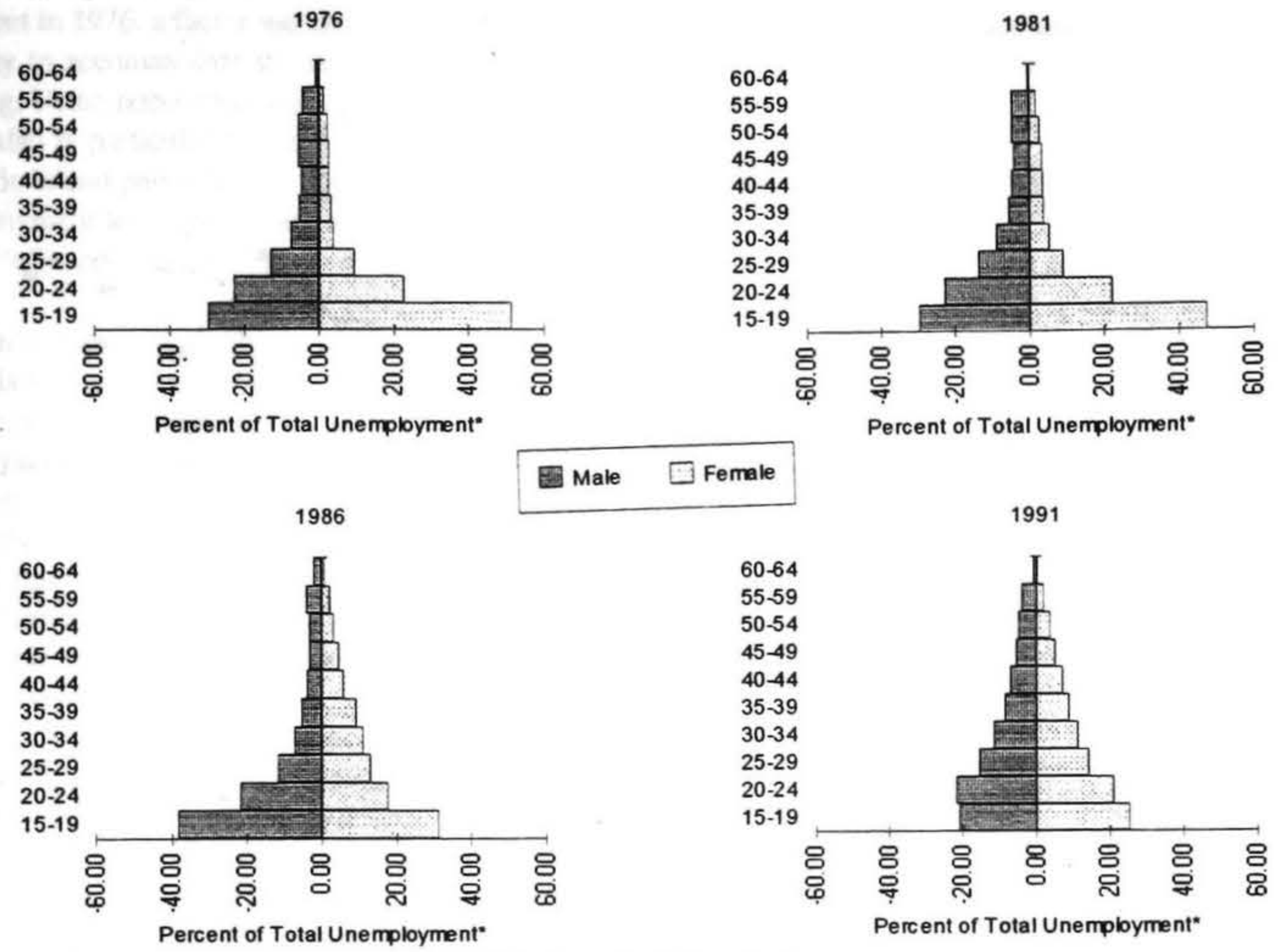

- For $1976+1981$ Unemployment refers to FULL-TIME only

For 1986 + 1991 Unemployment refers to Full-time PLUS Part-time

Figure 6. Unemployment* rates for 15-24 year (youth) and 35-54 (parental) age groups, by sex and ethnicity, 1976 to 1991, population denominator

PAKEHA
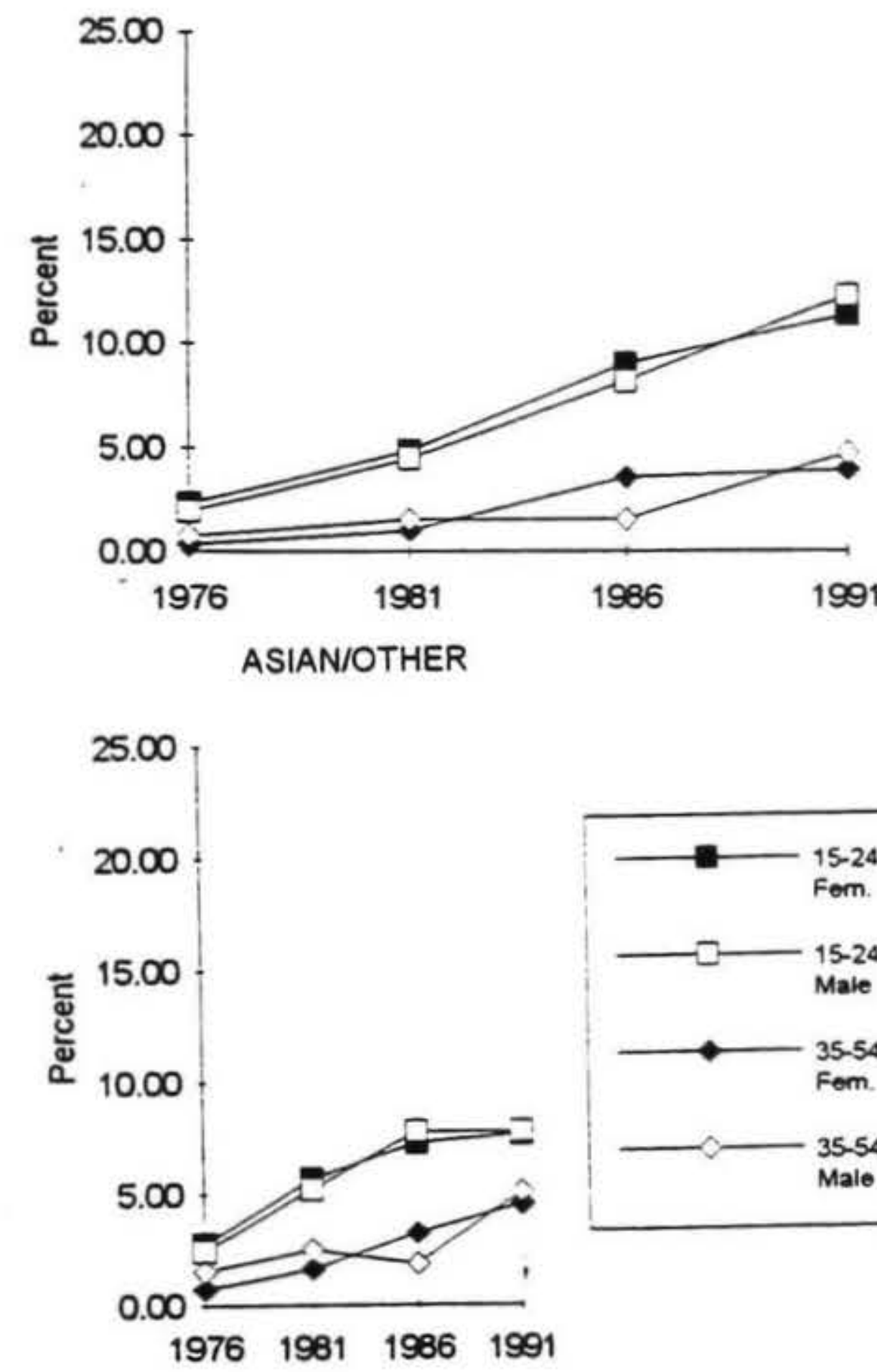

MAORI
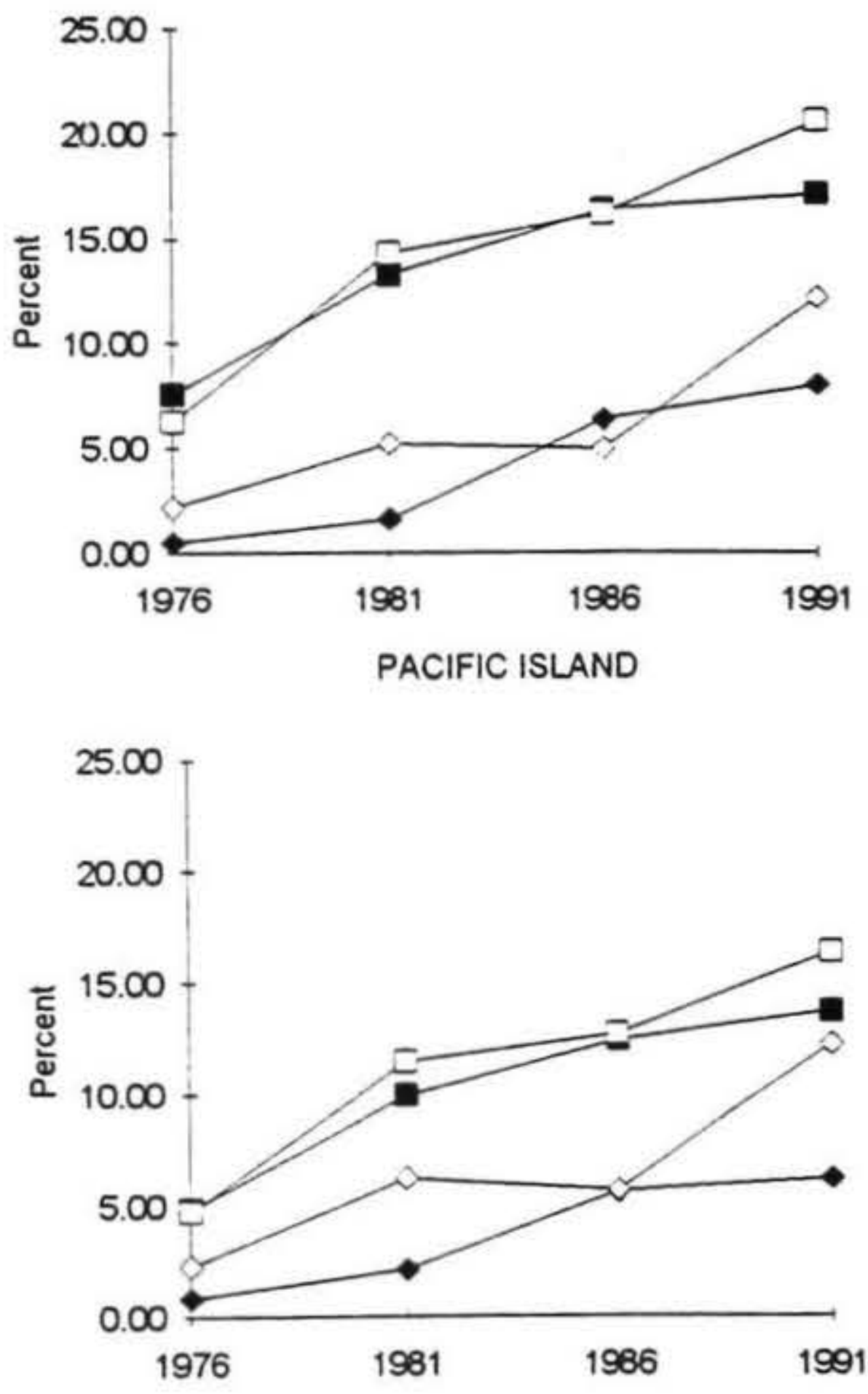

- For 1976 + 1981 Unemployment refers to FULL-TIME only

For $1986+1991$ Unemployment refers to Full-time PLUS Part-time 
Figure 7. Unemployment by cohort, female, labour force* denominator

PAKEHA

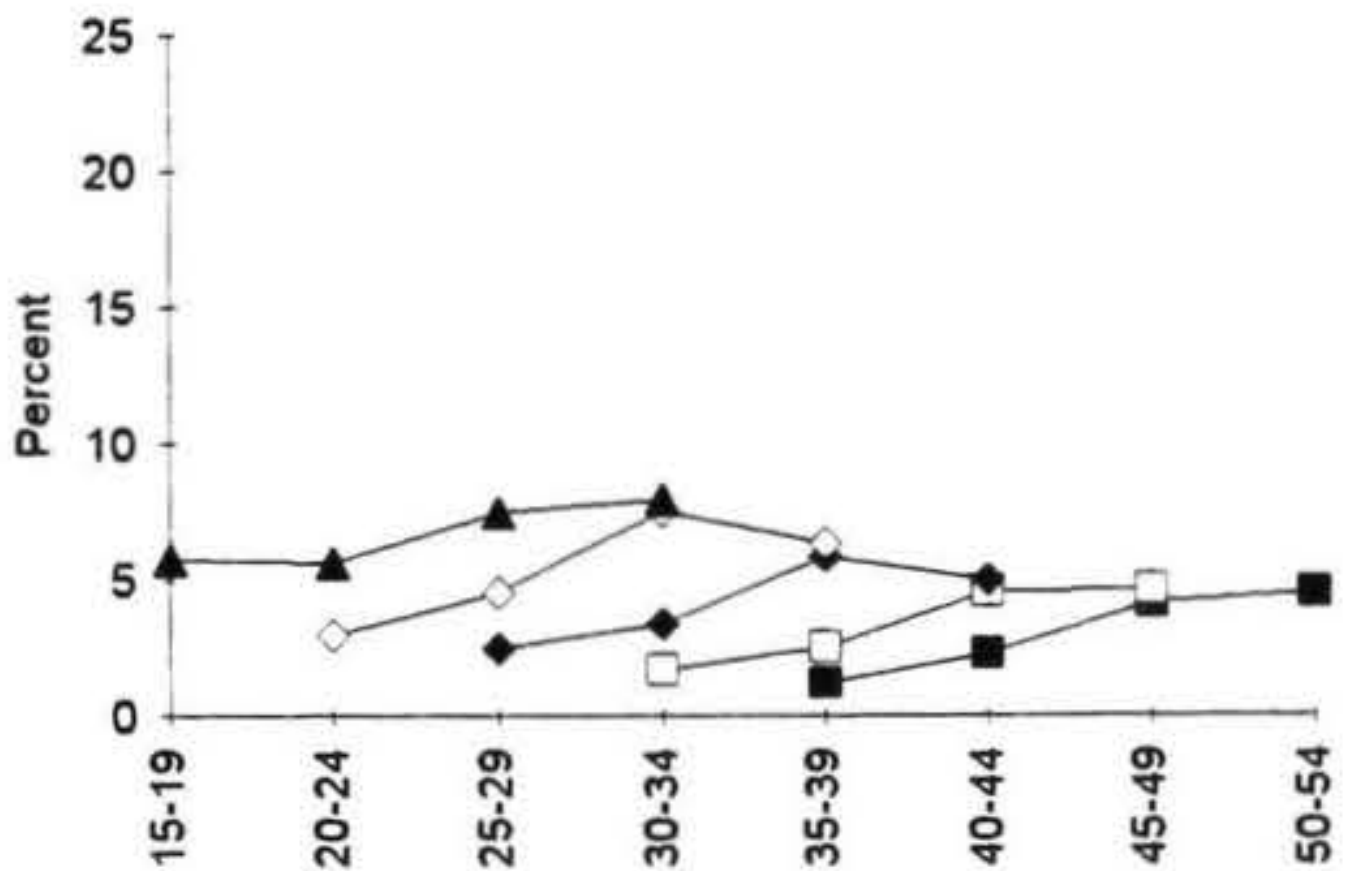

ASIAN/OTHER

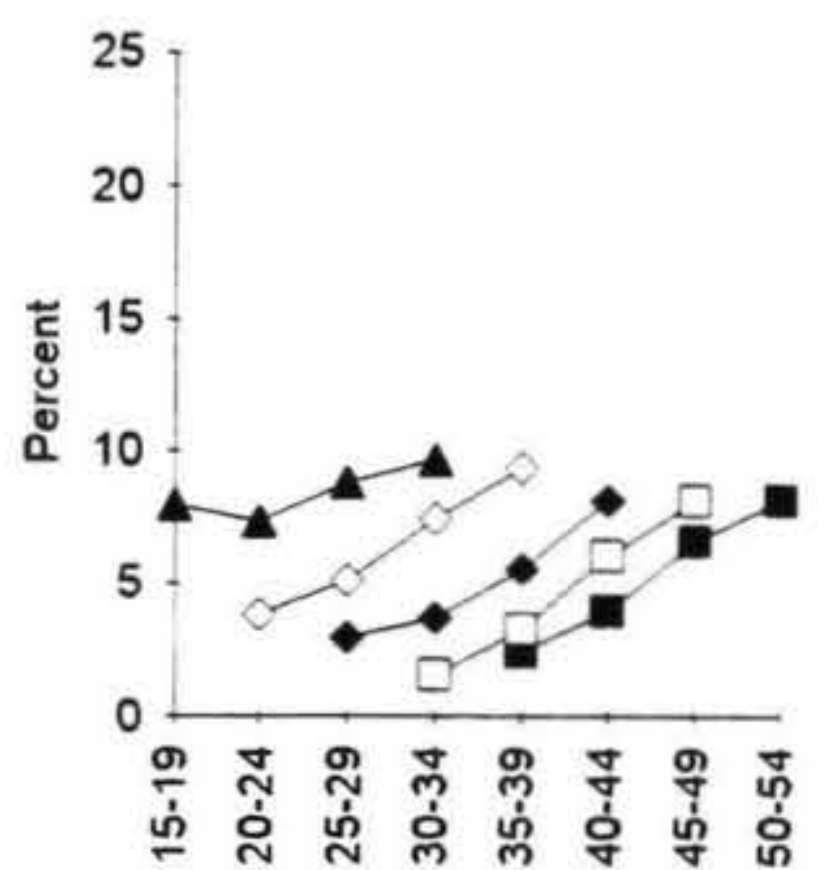

Cohort Born

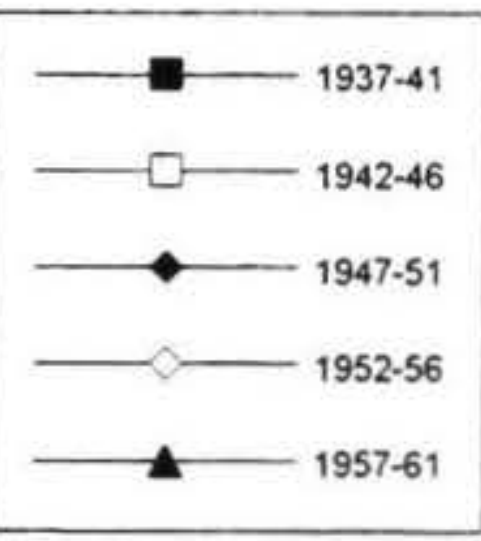

MAORI

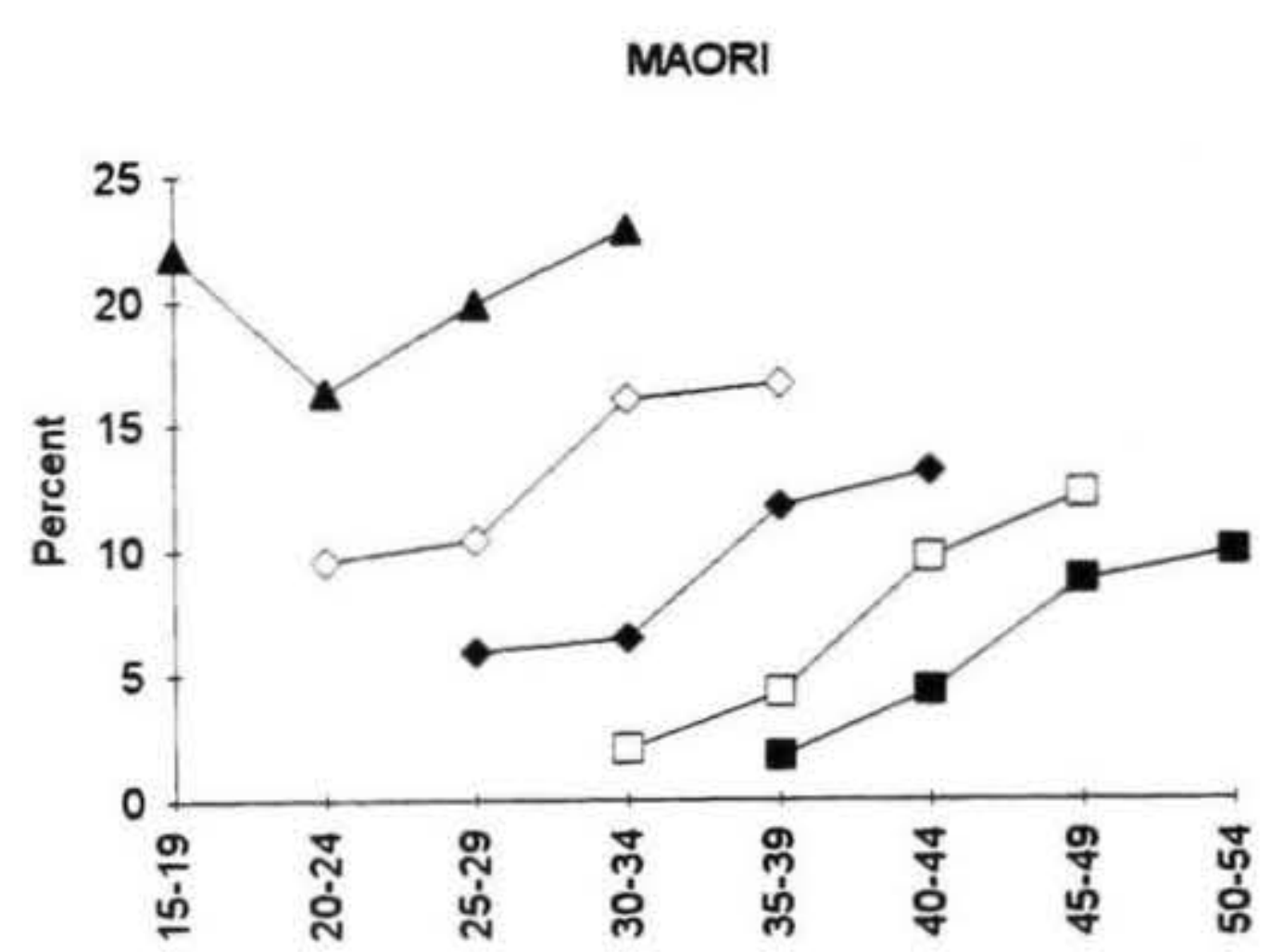

PACIFIC ISLAND

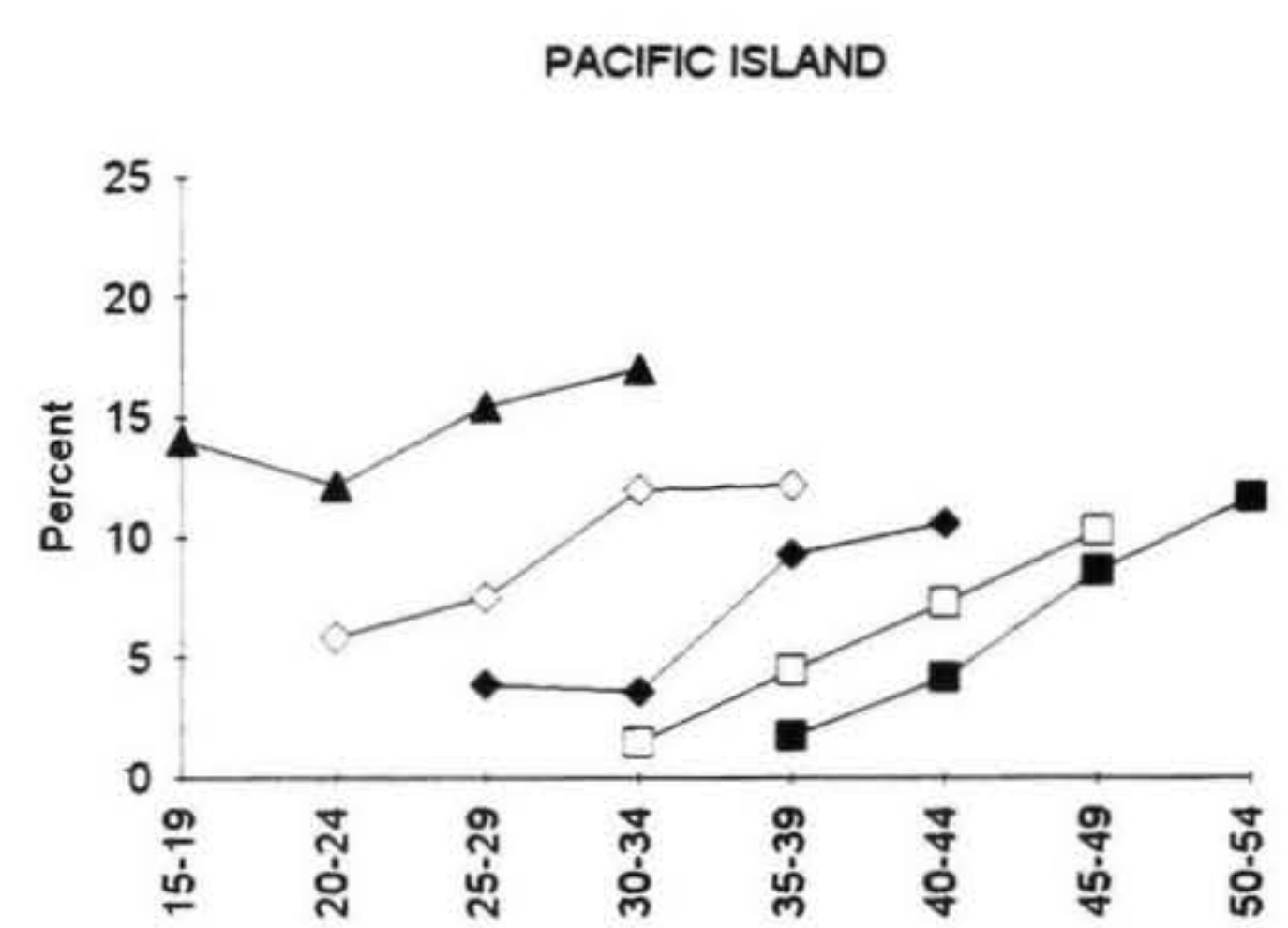

Figure 8. Unemployment by cohort, male, labour force* denominator

PAKEHA

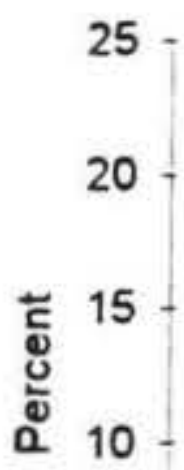

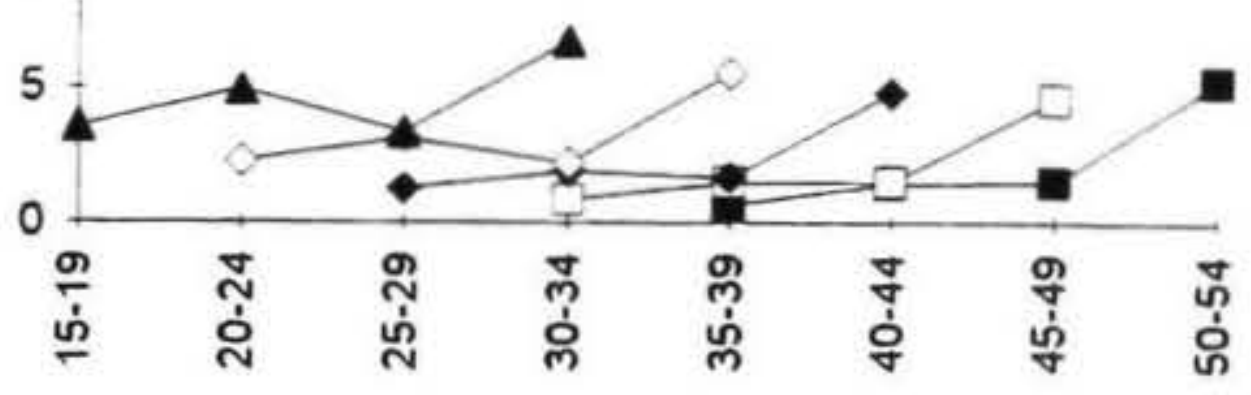

ASIAN/OTHER

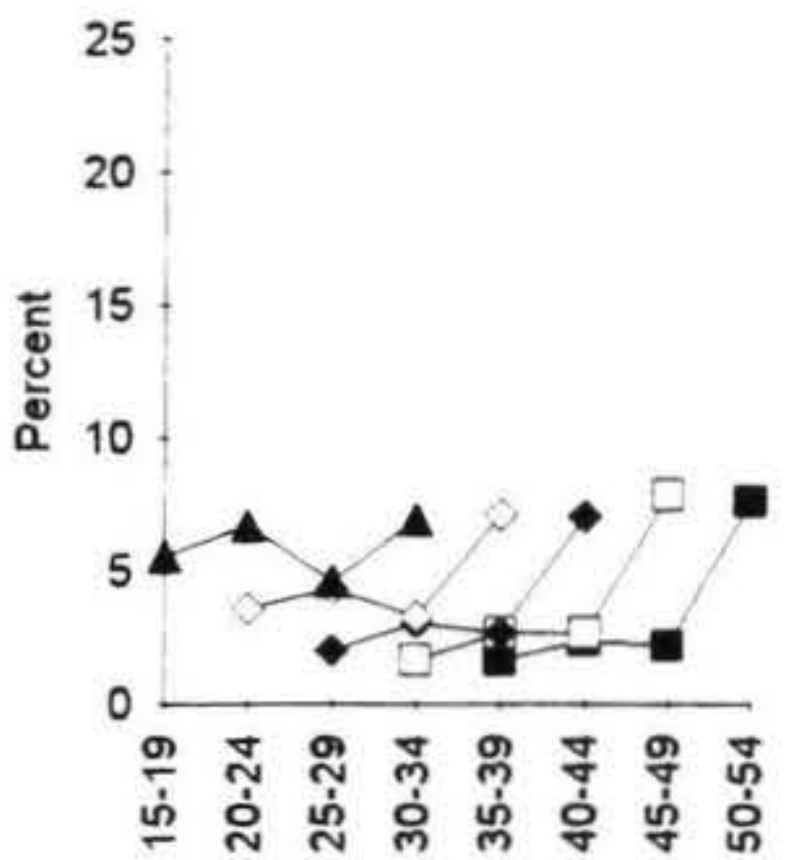

For $1976+1981$ Unemployment and Labour-force refers to FULL-TIME only

For $1986+1991$ Unemployment and Labour-force refers to Full-time PLUS Part-time 
to 56 per cent in 1991. The key 'parental-age' groups of current 15-24 year olds (those aged 35-54 years) carry around 26 per cent of all unemployment, up from 16 percent in 1976, a factor which undoubtedly affects their ability to accommodate the unemployment of their offspring. Using population-based rates, figure 6 shows that this also is particularly marked by ethnicity. Maori and Pacific Island parental-age males, for example, have unemployment levels which are almost as high as those of their 'offspring' generation

The implications for each ethnic population of these differentials become clearer when reviewed by cohort, an approach which permits us to trace the cumulative exposure of aggregate groups defined by age, sex, and ethnicity, as they pass through their life cycle. ${ }^{14}$ For example, and moving back to the labour force denominator for a moment, figure 7a shows that Maori women currently in their mid-thirties (the cohort born 1957-61) have been exposed to levels of unemployment double those of the Great Depression average $\left(8.5 \%^{15}, \mathrm{RCSP}, 1988: 172-3\right)$, ever since 1976; and their Pacific Island, and male counterparts (figure 7b), to levels not much lower. Moreover, instead of unemployment rates having fallen once past the younger age-groups, as the cross-sectional perspective would suggest, they have risen overall and far more so for Maori and Pacific Islanders than for Pakeha. Note that I use the LF measure here only to illustrate a specific point: depressionlevel unemployment must be seen as distress-level. This is particularly pertinent for the Maori and Pacific Island cohorts which are younger again, those born 1962-66 and 1967-71.

When the population-based measure is used (figure 8), the equivalent exposure for Maori (both males and females) in the 1957-61 cohort has never been less than one in thirteen, and currently, is one in eight females and one in six males. For Pakeha in this same cohort, exposure has never been more than one in twenty females and one in sixteen males: the current situation. Given the constraints of space it is impossible to go into much detail here, or to explain the finer points of the differences between the two measures. Perhaps most succinctly it can be noted that irrespective of the measure used, the most recent observation (representing 1991) for each Pakeha cohort seldom reaches above the rates experienced by the Maori and Pacific Island cohorts at their first and/or lowest observations; and that this has become increasingly true. ${ }^{16}$

Most of these data have been drawn from the past four censuses, the last of which was in 1991. Unemployment has shown some improvement in the 1993-94 year, but for 15-19 and 20-24 year olds, this is as yet minimal. Participation rates at these ages also remain below their 1991 levels (HLFS, June 1994). The objective of this part of the paper, however, was not to dwell on the various indices and their discrepancies, but to illustrate that the economic, labour force measure of unemployment does not necessar- ily give the full picture - it can conceal as much as it reveals - and that the conventional cross-sectional approach further confounds this situation. As noted, another factor which is very important for analysing unemployment is that of demographic change, and it is to this we now turn.

\section{Adding in demographic factors}

Demographic change has particular implications for understanding the dynamics of the labour market, because labour supply is usually considered in terms of 'propensity to work' (actual participation) at a single point in time, rather than the continuous dynamics of demographic supply. Between 1976 and 1991, the working-age population (15-64 years) grew by 16 per cent. At the beginning of this period, the largest of the baby boom cohorts (bom around 1961) arrived at the door of the labour market, at a rate of around 60,000 per year. Between then and now, more than 1.2 million individuals have turned $15-19$ years and also arrived, to a labour force itself numbering around 1.5 million. Over these same years, fewer than 600,000 have turned 60 and begun to leave the labour force. Thus, more than half a million new jobs were needed over the period to accommodate youth labour market entrants alone. Yet, as figure 9 illustrates, in 1991, only 5,000 more individuals (of all ages) than in 1976 identified themselves as working full time (mostly accounted for by a fall of 80,000 fulltime jobs at 15-19 years), while of the 98,000 new part-time positions which had appeared, only 25,000 had gone to youth .

Moreover, while those currently aged 15-24 were born in the early 1970s, when Pakeha birth rates were in fact at their lowest since the peak of the baby boom, because of the convergence of other demographic factors ${ }^{17}$ their actual numbers are only slightly smaller (around $-8 \%$ on reaching the labour market) than those of their 1961 counterparts. When the former began to arrive at the labour market in the mid-1980s - the very moment that the massive and simultaneous exercises in 'labour shedding' and State facilitation of free market forces began in earnest- they found a labour force already engorged by the large cohorts which had preceded them (refer again to endnote 9). For Maori and Pacific Islanders - who did not even take part in the baby boom - the situation is even worse. Due to significant differences in the timing and velocity of their respective fertility declines, and for $\mathrm{Pa}$ cific Islanders the added effects of migration, in 1991 their largest cohorts were still entering the labour market. At this time, the Maori 15-24 year population was 22 per cent larger than in 1976, while for Pacific Islanders it was 130 per cent.

This sort of simple 'political arithmetick' 18 makes notions of 'dependency culture', lack of skills etc., rather invidious. Certainly, it illustrates a factor that the invisible hand is ill-equipped to deal with: the differing lag-times of population and economic cycles; and it is here that I see a major potential for polarisation. To understand this it is 
Figure 9. Size of working-age, fulltime and part-time populations, 1976-1991

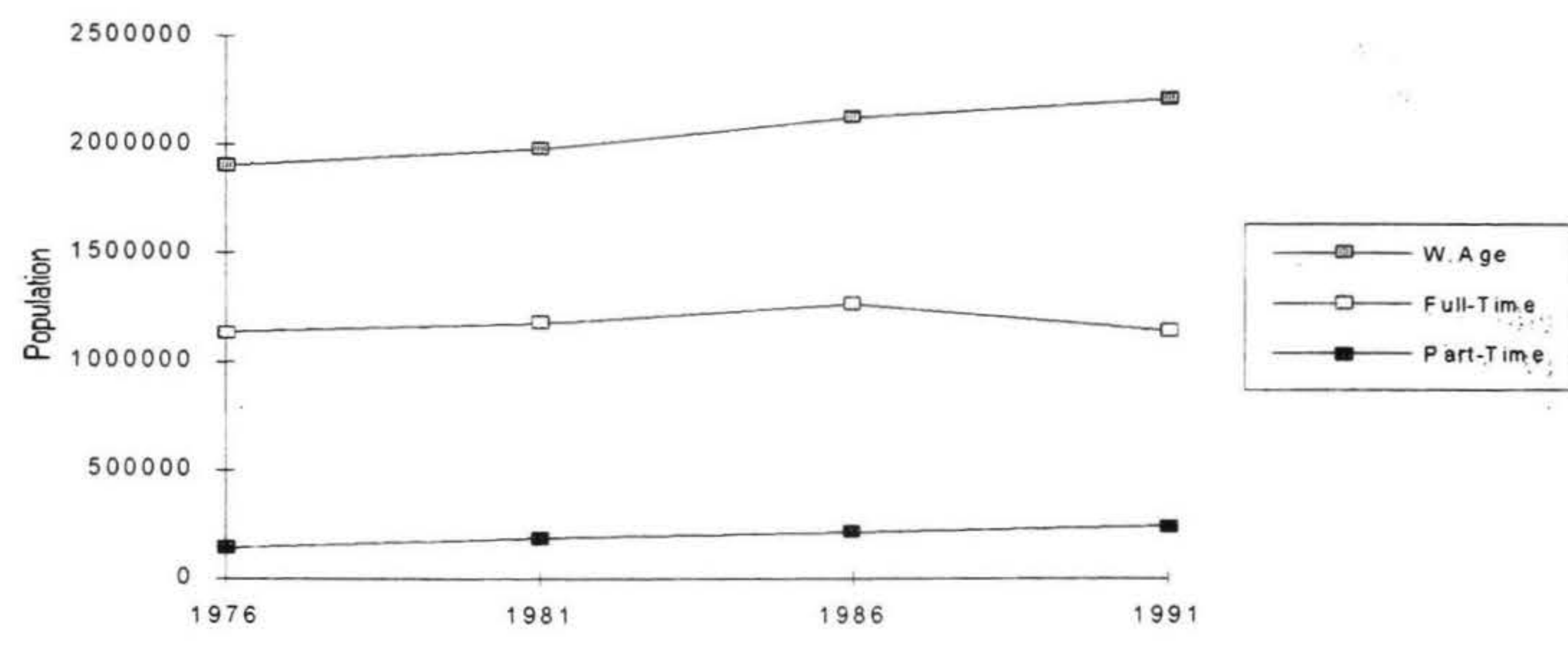

necessary to shift the present focus from population growth to population composition. First, the differences in fertility and migration translate into different age-structures for each of New Zealand's sub-populations. The median age of both the Maori and Pacific Island populations is around 21 years; for Pakeha it is 33 years.. These differences exacerbate the effects of higher age-specific unemployment rates. That is, it is not just that Maori and Pacific Island age-specific unemployment rates are higher, but that unemployment is inversely proportioned to age, and a greater proportion of these populations are younger. Second, when some of the more recent policy responses are added to the analysis, their considerably greater impact on the Maori and Pacific Island populations can be appreciated. In 1991, 34 per cent of the adult Maori population (15+ years) and 32 per cent of the adult Pacific Island population were aged 15-24 years, compared with only 19 per cent of Pakeha. The raising of the age of eligibility for the adult rate of unemployment benefit to 25 years was thus extremely discriminatory on this point alone, without even considering the ethnic maldistribution of unemployment. To really appreciate the potential implications of these composition effects, however, we need to turn to some micro-level analogues of demographic change.

Reflecting the differing age-structures, in 1991 three quarters of Maori households and 83\% of Pacific Island households had usually-resident children, compared with less than half of Pakeha households; and within these households, 84 per cent of Maori and $86 \%$ of Pacific Island, but only 69 per cent of Pakeha households, had children under the age of 16 years (Jackson and Pool, 1994). Of older offspring, population ratios show that Maori and Pacific Islanders in the 35-54 year parental-age group were almost twice as likely as their Pakeha counterparts to be associated with a 15-24 year old. Even if the unemployment experiences of these populations were the same, there would be considerable differences in their youth depend- ency ratios. However, as shown, the younger the 'parent', the more likely he or she is to be unemployed, and this is particularly pertinent for Maori parents who, on average, have their children at considerably younger ages than Pakeha. ${ }^{19}$ Clearly, Maori and Pacific Island parents will be in a considerably worse position than Pakeha parents, to support their unemployed youth.

When we add the fact that Maori women in the 1957-61 cohort also have, for example, the highest levels of sole parenting, both cumulatively and currently, and the third taining to the same 'scale' (the actual population at age $\mathrm{x}$ ) can be more readily added, thus providing a far more comprehensive base upon which to develop appropriate policy responses. There are of course many such variables. In my (ongoing) research which compares the experiences of forty parental-age cohorts across a broad range of population-based socio-demographic indicators, only four Maori and no Pacific Island cohorts appear in the twenty most advantaged positions, while only two Pakeha cohorts fall into the twenty least advantaged (Jackson, 1994). There is significant evidence of 'eth-class' (Miles and Spoonley, 1982) and polarisation, both of which stand to be exacerbated by current policy directions.

\section{Conclusion}

Conventional age, sex, and ethnic comparisons of unemployment based on labour market participation are seriously compromised, in that they conceal important differences in participation between these groups. Whilst they may be acceptable for the purposes of labour market analysis, where they influence the interpretation of and response to unemployment, their limitations need to be fully appreciated. For comparative purposes a populationbased, or social, measure, offers a more refined index, and can more readily identify the extent to which a sub- 
population must accommodate the consequences of unemployment.

For some groups high unemployment is not an experience isolated to a point in time, but one which can be experienced through time. The Maori and Pacific Island cohorts which contain the younger parents of current 15-24 year olds (and forthcoming labour market entrants) have themselves experienced high and increasing levels of unemployment, ever since their own youth. For many the cumulative effects of this, in combination with other highly relevant demographic factors, must seriously affect their ability to support their unemployed youth, as required through the recent changes to the welfare state .

Finally, many years pass between the birth of a cohort and its eventual arrival at the labour market. Yet once 'on the ground', the cohort's size, characteristics, and the potential implications of these can be estimated over all of these years, a point clearly made by the OECD. Given New Zealand's control over migration, cohort size is the one thing which is more or less predictable, and to which policies can be addressed to lessen the effects of changes in the political economy. That the architects of these changes responded to the unemployment associated with them in the manner they did means that not only the unemployment, but the policies also, will have a differentiating effect on the population. In incorporating demographic change, a social measure of unemployment would go some distance towards providing a comprehensive base for the development and evaluation of future socio-economic policy.

\section{Future research}

Each of these issues invites future research. As I have written this paper, focusing so much on the denominator aspects of measuring unemployment, I have become increasingly uncomfortable with the numerator. As noted, only those who are in the labour force can be enumerated as unemployed, yet, as the comparison between the labour force-based and the population-based measures, and other studies, illustrate, a sizable number of 'potentially unemployed' have, since around 1986, simply not entered the labour force. In order to gain a more valid social measure of the unemployment-related dependency or vulnerability being carried by each sub-population group, it may be more useful to move to a numerator which includes both the unemployed, and those not in the labour force, as Brian Easton is currently doing (personal communication).

It is possible that the use of such population-based social measures of labour force status may further permit the development of a composite socio-demographic index, wherein the complexities of the social outcomes of Free Market policies may be able to be comprehensively identified and monitored. ${ }^{20}$ The cohort analysis, also, has much to offer labour market analysts in terms of life-time person-hours in or out of the labour force, using fulltime and part-time status, etc., and would seem a very necessary basis for any analysis by sex. Finally, the differing momenta of demographic and economic cycles are increasingly interesting. Data from both fields demonstrate short and long run trends which appear to sometimes parallel, sometimes mirror, each other. The theoretical and explanatory frameworks of each may thus have much to offer the other, and it may be only through such interdisciplinary, preferably collaborative, research, that these phenomena will be satisfactorily explained.

\section{References}

Bolger, J.B. 1981 Jobs and People. The Government's Employment Strategy. Wellington: Government Printer, June.

Bolger, J.B., Richardson, R. and Birch, W.F. 1990 Economic and Social Initiatives. Statements to the House of Representatives. Wellington, December.

Boston, J. and Dalziel, P. (eds)., 1992The Decent Society? Essays in Response to National's Economic and Social Policies. Auckland: Oxford University Press.

Dixon, S. 1993 Alternative Measures of Employment and Unemployment. Key Statistics, March:9-16.

Easton, B (ed). 1989 The Making of Rogernomics. Auckland: Auckland University Press.

Horsfield, A., and Evans, M. 1988 Maori Women in the Economy. Te Ohu Whakatapu Ministry of Women's Affairs, Wellington.

Household Labour Force Survey (HLFS) Wellington: Department of Statistics.

Jackson, N.O. 1994 Youth Unemployment and the Core Family.Population, Policy, and Political Economy. Unpublished Masters Thesis, University of Waikato.

Jackson, N.O. and Pool, I. 1994 Fertility and Family Formation in the Second Demographic Transition. New Zealand Trends and Patterns. Report prepared for Social Research and Development Unit, Wellington.

Jackson, N.O., Pool, I., and Cheung, M.C. 1994 Maori andNon-MaoriFertility: Convergence,Divergence, or Parallel Trends? Discussion Paper No.3. Population Studies Centre, University of Waikato, Hamilton, December.

Loomis, T. 1990 Pacific Migrant Labour. Class and Racism in New Zealand. Aldershot: Avebury.

Miles, R., and Spoonley, P. 1985 The Political Economy of Labour Migration: An Alternative to the Sociol- 
ogy of 'Race' and 'Ethnic Relations' in New Zealand. Australia and New Zealand Journal of Sociology, 121(1), March.

New Zealand Business Roundtable. 1988 Labour Markets and Employment. Statements on Labour Relations. Wellington: New Zealand Business Roundtable.

New Zealand Business Roundtable. 1990, Unemployment. Realities and Illusions. Wellington: New Zealand Business Roundtable, December.

New Zealand Employment Service (NZES). $1992 \mathrm{La}$ bour Market Information Handout. Operations and Policy Unit, July.

Organisation for Economic Co-operation and Development (OECD). 1985New Policies For the Young. Paris.

Organisation for Economic Co-operation and Development (OECD). 1989 Economic Surveys. New Zealand 1988-19. France.

Pool, I., and Sceats, J. 1981 Fertility and Family Formation in New Zealand. An Examination of Data Collection and Analyses. Wellington: Ministry of Works and Development, August.

Population Monitoring Group (PMG). 1986 The New Zealand Population: Change, Composition, and Policy Implications. Report No.4. Wellington:New Zealand Planning Council.

Rankin, K. 1990 New Zealand's Labour Supply in a Long Term Perspective. A paper presented to the New Zealand Association of Economists Sesquicentennial Conference, University of Auckland, August 22.

Royal Commission on Social Policy (RCSP). 1988 The April Report. New Zealand Today. Volume 1. Wellington: Royal Commission on Social Policy.

Shipley, J. et.al. 1991aWelfare That Works. A Statement of Government Policy on Social Assistance. Wellington: Government Printer.

Shirley, I. Easton, B. Briar, C. and Chatterjee, S. 1990 Unemployment in New Zealand. Dunmore Press.

Shirley, I. 1993 Experiments in the New Zealand Laboratory. Paper presented at the Conference on Comparative Research on Welfare States in Transition, Oxford University, 9-12 September.

Spoonley, P. 1988 Racism and Ethnicity. Auckland: Oxford University Press.
Thompson, B. 1985 The Industrial Structure of the Workforce. In Population of New Zealand. Country Monograph Series No.12. Volume 2. ESCAP, United nations.

Touraine, A. 1991 Preface. In Facing the Future. Young People and Unemployment around the World.Paris, UNESCO.

Treasury. 1987 Government Management. Brief to the Incoming Government, Vol 1.

Walsh, P. 1992 The Employment Contracts Act. In Boston, J. and Dalziel, P. The Decent Society? Essays in Response to National's Economic and Social Policies. Auckland: Oxford University Press.

Westrate, C. 1956 The Economic Record. Economic Society of Australia and New Zealand, Melbourne University Press, May:139-141.

\section{Notes}

1 Certainly little was mentioned about the active recruitment of these people for the specific labour needs of capital in the preceding years (Miles and Spoonley, 1985; Spoonley, 1988; Loomis, 1990).

\section{Around 50,000 registered unemployed.}

3 Around 100,000 registered unemployed.

4 With around 180,000 registered unemployed, the annex to the 1991 Budget which outlined the restructuring of the welfare state ('Welfare That Works', Shipley et al., 1991) recorded that large numbers of individuals appeared to prefer a culture of dependency ahead of self reliance, a situation which the State, 'in the interests of all New Zealanders' needed to provide 'sufficient motivation to move from State dependence to independence' (Shipley et al., 1991:4,25). Indeed, in this 87-page document it is possible to count no fewer than 72 references which charge that beneficiaries are intent on cheating the system. The phrase 'fraud and abuse', for example, is used fourteen times, and a rather divisive distinction between those 'ordinary, honest New Zealanders' whose taxes provide the welfare benefits, and those who receive them, is made in thirteen places. The word unemployment, used about six times, is generally accompanied by the somewhat circular suggestion that benefits are its root cause.

5 The architects of the changes made this inter-relationship quite explicit: 'For many people the generosity of the benefit system has become a poverty trap. Benefit payments have been hight enough in relation to wages that for many people there has been little encouragement to take on paid work, and employers have been unable to attract workers at rates which would maintain the viability of their businesses. Our changes to benefits and the reforms of the labour market through the Employment Contracts Act are setting the scene for a new and more effective approach. 
(iii) only 74 per cent of those who described themselves as unemployed in the 1991 census were officially acceptedas such (Jackson, 1994). Thus, whenever we are talking about 'unemployment', we are clearly dealing with a serious underenumeration. The 'jobless' is probably more accurate, but this also excludes (i) and (ii).

1 The process of standardisation, where the experience $\mathrm{f}$ the one population is computed as if it had the same age-s tructure as the other, is insufficient to gain this perspective.

12 Unless sourced otherwise, all data used in this paper come from my Masters thesis (Jackson 1994) which used a customised census database compiled by Statistics NZ for the Population Studies Centre, University of Waikato. For 1976 and 1981, 'unemployment' and 'labour force' refers to Fulltime only. For 1986 and 1991, they refer to Fulltime PLUS Part-time. Ethnic classification is based on an hierarchical procedure which prioritises first to Maori, then Pacific Island, then 'Other', then Pakeha

3

3 The addition of part-time into the labour force has nevertheless addressed some important issues, for example, the contribution that women make to the labour force and the economy.

14 Demographic cohorts are not 'closed' populations. People enter them by migration and leave by migration and death. This is, however, more or less irrelevant to the present discussion, which is concemed with the impact of unemployment and unemployment-related policy changes on each sub-population as a whole. It is, nevertheless, fair to assume that a core of the same people are present for much of their life cycle.

15 It is difficult to be definitive about this level. Thompson (1985:132) gives this as 12\%; Rankin (1990:2) as 33\%; while Westrate in the Economic Record (1956:140) records the September 1932 level as $10.8 \%$ of the male labour force. Each are based on different criteria, and tend to pertain to males. The Royal Commission on Social Policy (1988:172-3), however, records the conservative $8.5 \%$ used here.

16 In the population-based measures the last age-span of the youngest cohorts reflects a point made earlier, that large numbers of 'potentially unemployed' youth are undoubtedly missing from the numerator. Thus these trajectories differ (between the two measures) for the younger cohorts more than they do for the older cohorts.

17 The first large cohorts of the baby boom began to have their own children, and whilst they were having fewer children than their own mothers had, there were more of them (women reaching childbearing age).

18 'Political Arithmetick' was a phrase coined by William Petty in the late 1600 s. The concept refers to the interest of the State in the composition of its population, and its principles underlie modern political economy.

19 Currently more than seven years separate the peak childbearing years of Maori and non-Maori, these occurring at approximately 21 years for Maori and 28 for nonMaori (Jackson, Pool, and Cheung, 1994)

20 The topic of my doctoral research, currently being undertaken at the Australian National University, Canberra.

\section{Author}

Natalie Jackson is a Research Fellow at the Population Studies Centre at Waikato University, PO Box 3105, Hamilton. 
